\title{
Zinc Deficiency is Associated with Poor Glycemic Control
}

\author{
Muhammad Farooq
}

\begin{abstract}
Objective: To assess the level of zinc in type 2 diabetes mellitus and its relation to glycemic control.

Study Design: Descriptive cross-sectional study.

Place and Duration of Study: Department of Medicine, Dallah Hospital, Riyadh, KSA, from May 2014 to June 2015.

Methodology: This study employed 200 diabetic and 192 control subjects. The demographic data was taken from all 392 subjects; and laboratory investigations like, fasting blood sugar (FBS), glycosylated hemoglobin (HbA1C), and serum zinc level were done. The groups were divided into diabetic and control, normal zinc group ( $>70 \mathrm{mcg} / \mathrm{dL}$ ) and low zinc group $(<70 \mathrm{mcg} / \mathrm{dL}$ ) levels.

Results: The mean age for low zinc group was $51.99 \pm 10.51$ years and for normal zinc group $52.87 \pm 10.29$ years $(p=0.408)$. The male to female ratio was $0.93: 1$ in low zinc group and 1.3:1 in normal zinc group ( $p=0.082)$. The mean serum zinc was significantly lower in diabetic patients $(66.54 \pm 11.328 \mathrm{mcg} / \mathrm{dL})$ than in healthy subjects $(82.63 \pm 12.194$ $\mathrm{mcg} / \mathrm{dL}, \mathrm{p}<0.001)$. The mean FBS was $139.84 \pm 30.68 \mathrm{mg} / \mathrm{dL}$ in low zinc level group in contrast to $104.88 \pm 26.12 \mathrm{mg} / \mathrm{dL}$ in normal zinc level group $(p<0.001)$. The mean $\mathrm{HbA1}$ c was $8.91 \pm 2.16 \%$ in low zinc level group in contrast to $5.696 \pm 2.3$ in normal zinc level group $(p<0.001)$. The serum zinc level was negatively associated with FBS and HbA1c.

Conclusion: This study concluded that low zinc level was associated with Type $2 \mathrm{DM}$, and serum zinc level was negatively associated with poor glycemic control.
\end{abstract}

Key Words: Zinc, HbA1c, Trace element.

\section{INTRODUCTION}

The number of patients with diabetes mellitus (DM) increased from 108 million in 1980 to 422 million in 2014 and increasing day by day worldwide. ${ }^{1}$ The worldwide prevalence of DM in adult population is more than $8.5 \% .^{1}$ In Saudi Arabia, more than 3 million people ( $>16 \%$ of population) have DM. ${ }^{2}$ Most of the DM patients are classified as type $2 \mathrm{DM}$ in adult population. The effect of insulin resistance and relative deficiency of insulin secretion leads to hyperglycemia. The chronic hyperglycemia increases oxidative stress by production of free radicals (oxidants) and reduction in antioxidant defense system. This leads to oxidative cellular injury damaging metabolism of lipid, proteins and DNA, resulting in cellular dysfunctions. ${ }^{3}$

Zinc is a trace element that acts as co-factor for synthesis, storage and secretion of insulin by pancreas. The predominant effect of diabetes on zinc homeostasis is hypozincemia, which may be the result of hyperzincuria or decreased intestinal absorption of zinc or both. ${ }^{4}$ Zinc has an important role in the glucose utilization by muscle and fat cells. 5 It is required as a cofactor for the function of intracellular enzymes that may be involved in protein, lipid and glucose metabolism. ${ }^{5}$

Department of Internal Medicine, Dallah Hospital, Riyadh, Kingdom of Saudi Arabia

Correspondence: Dr. Muhammad Farooq, Department of

Internal Medicine, Dallah Hospital, Riyadh, KSA

E-mail: drfarooqsattardhedhi@yahoo.com

Received: February 15, 2018; Accepted: September 22, 2018
Zinc may be involved in the regulation of insulin receptor-initiated signal transudation mechanism and insulin receptor synthesis. ${ }^{5}$ Zinc also plays a key role in the synthesis, storage, and secretions of insulin by pancreatic tissue, and it accounts for the conformation integrity of insulin in its hexameric crystalline form. 6 Zinc may participate as an integral component of several antioxidant enzymes. Many of the complications of diabetes may relate to an increase in intracellular oxidant and free radicals associated with decrease in intracellular zinc and zinc dependent antioxidant enzymes. 6

Anderson et al. reported that $30 \%$ patients with DM found to be zinc deficient. ${ }^{7}$ Tripathy et al. had reported zinc depletion in type 2 DM. ${ }^{8}$ On the contrary, Mumza et al. reported high zinc level in type 2 DM patients. ${ }^{9}$

Therefore, this study was conducted to determine the serum zinc status and its relationship with age, gender, body mass index (BMI), systolic blood pressure (SBP), diastolic blood pressure (DBP), fasting blood sugar (FBS), glycosylated hemoglobin ( $\mathrm{HbA1C}$ ) and lipid levels in type 2 DM patients.

\section{METHODOLOGY}

This cross-sectional study was done at Outpatient Department (OPD) of Dallah Hospital, Riyadh, Kingdom of Saudi Arabia, from May 2014 to June 2015. The sample size was calculated by using sample size calculating formula available on website 10 by keeping $95 \%$ confidence level and $5 \%$ margin of error for population of $1,00,000$. The minimum sample size was 383 subjects. 
Patients above age of 20 years with type 2 diabetes for more than 2 years presented to Diabetic Clinic during study period from May 2014 to June 2015 and selected as randomly one in three till the sample size completed. The controls were selected on voluntary basis from the family of patients or other people who were not diabetic and matched with gender and age of patients. Patients with type 1 diabetes, pregnant patients, patients with chronic kidney disease stage 3 or less (creatinine clearance less than $30 \mathrm{ml} / \mathrm{min} / 1.73 \mathrm{~m} 3$ ), patients taking diuretics or vitamins or mineral supplements were excluded from the study. Informed consent was taken from all subjects and Hospital Ethical Committee approval was also acquired.

The age in years, gender, height in centimeter $(\mathrm{cm})$, and weight in kilogram $(\mathrm{kg})$ were recorded in patient's file by two OPD nurses in OPD triage room. The body mass index (BMI) was calculated by using the formula: $\mathrm{BMI}=$ Weight in kilogram divided by height in meter square. The blood pressure was recorded in both arms after five minutes of sitting and the higher one was recorded for data analysis. The 12-hour fasting blood sample was taken for lipid profile, FBS, HbA1c, and serum zinc level. The FBS was done by the enzymatic calorimetric method and $\mathrm{HbA} 1 \mathrm{c}$ estimation was done by fast ion exchange resin method in the same hospital. Serum cholesterol and LDL were done by cholesterol oxidase method and serum triglyceride by glycerol peroxidase method on auto analyzer in the same hospital. Serum zinc was measured colorimetrically with 2-(5-Bromo-2Pyridylazo)-5-(N-Propyl-N-Sulfopropylamino-) phenol by Bioscientia, Germany. ${ }^{11}$ The reference value of serum zinc was $70 \mathrm{mcg} / \mathrm{dL}$ to $120 \mathrm{mcg} / \mathrm{dL}$. The groups were divided into normal zinc ( $>70 \mathrm{mcg} / \mathrm{dL})$ and low zinc ( $<70$ $\mathrm{mcg} / \mathrm{dL}$ ) levels. Another group division was diabetic and control subjects.

These two groups were analyzed by using the Statistical Package for Social Sciences (SPSS) version 22.0 for Windows from IBM. Chi-square test was done for qualitative data by using cross tab; and student's t-test was used to compare the means of zinc level, FBS, $\mathrm{HbA} 1 \mathrm{c}$, cholesterol, triglycerides, and LDL of diabetic subjects with their controls. Student's t-test was done to compare means on different variables between groups of good glycemic control and poor glycemic control in diabetic patients. Pearson's linear coefficient was used to determine the correlation of zinc with age, BMI, systolic BP, diastolic BP, FBS, HbA1c, cholesterol, triglycerides and LDL in diabetic and control groups separately. A $p$-value of equal to or less than 0.05 $(p \leq 0.05)$ was considered as statistically significant.

\section{RESULTS}

Among the 392 subjects, $51 \%(n=200)$ had type $2 \mathrm{DM}$ while $49 \% \quad(n=192)$ were age and gender matched
Table I: Demographic data with low and normal zinc levels.

\begin{tabular}{|c|c|c|c|c|}
\hline & $\begin{array}{l}\text { Low Zinc } \\
\text { Level }\end{array}$ & $\begin{array}{c}\text { Normal Zinc } \\
\text { Level }\end{array}$ & Total & P-value \\
\hline \multicolumn{5}{|l|}{ Age } \\
\hline$<50$ years & 88 (22\%) & $98(25 \%)$ & $186(47 \%)$ & \\
\hline$>50$ years & $94(24 \%)$ & $112(29 \%)$ & 206 (53\%) & 0.739 \\
\hline \multicolumn{5}{|l|}{ Gender } \\
\hline Male & $88(22 \%)$ & $120(31 \%)$ & $208(53 \%)$ & \\
\hline Female & $94(24 \%)$ & $90(23 \%)$ & $184(47 \%)$ & 0.082 \\
\hline \multicolumn{5}{|l|}{$\mathrm{BMI}$} \\
\hline$<30$ & $63(16 \%)$ & 75 (19\%) & $138(35 \%)$ & \\
\hline$>30$ & $119(30 \%)$ & $135(35 \%)$ & $254(65 \%)$ & 0.107 \\
\hline \multicolumn{5}{|l|}{ Subjects } \\
\hline Diabetic & $152(39 \%)$ & $48(12 \%)$ & $200(51 \%)$ & \\
\hline Control & $30(8 \%)$ & $162(41 \%)$ & $192(49 \%)$ & $<0.001$ \\
\hline \multicolumn{5}{|l|}{$\mathrm{HbA1C}$} \\
\hline$<7 \%$ & $30(8 \%)$ & $162(41 \%)$ & $192(49 \%)$ & \\
\hline$>7 \%$ & $152(39 \%)$ & $48(12 \%)$ & $200(51 \%)$ & $<0.001$ \\
\hline \multicolumn{5}{|l|}{ FBS } \\
\hline$<110 \mathrm{mg} / \mathrm{dL}$ & $24(6 \%)$ & $191(49 \%)$ & $215(55 \%)$ & \\
\hline$>110 \mathrm{mg} / \mathrm{dL}$ & $109(28 \%)$ & $68(17 \%)$ & $177(45 \%)$ & 0.476 \\
\hline
\end{tabular}

controls. Table I shows the frequency and distribution of demographic data with relation to low and normal zinc levels.

The mean age for type 2 DM group and control group was almost same and there was no significant statistical difference between the two groups $(p=0.806$, Table II). The mean age for low zinc group and normal zinc group was same and there was no statistically significant difference between the two groups $(p=0.408$, Table II). Age was categorized into two groups $<50$ years and $>50$ years, and had no statistically significant association with serum zinc level $(p=0.739)$ and age group. The male to female ratio in diabetic group was $0.9: 1$, while in control group it was 1.3:1. The male to female ratio in low-zinc group it was 0.93:1, and in normal-zinc group it was 1.3:1. There was no statistical significant difference found between the groups regarding gender $(p=0.082)$. The mean BMI for diabetic group was $32.63 \pm 5.88$ $\mathrm{Kg} / \mathrm{m}^{2}$ and for control group $32.00 \pm 6.03 \mathrm{Kg} / \mathrm{m}^{2}$; and there was no significant difference noted in diabetic and control groups $(p=0.292)$; and there was no significant difference in low-zinc group (32.70 $\pm 6.31 \mathrm{mcg} / \mathrm{dL})$ and normal-zinc group (31.99 $\pm 5.62 \mathrm{mcg} / \mathrm{dL}, \mathrm{p}=0.242)$ regarding $\mathrm{BMI}$ in this study. The mean systolic and diastolic BP were significantly higher $(p<0.001)$ in type 2 DM subjects and subjects with low zinc level as compared to the controls and normal zinc level subjects, respectively (Table II).

Mean serum zinc was significantly lower in diabetic patients $(66.54 \pm 11.328 \mathrm{mcg} / \mathrm{dL})$ compared to healthy subjects $(82.63 \pm 12.194 \mathrm{mcg} / \mathrm{dL}, p<0.001$, Table II). Mean fasting blood sugar was $92.42 \pm 7.82 \mathrm{mg} / \mathrm{dL}$ in healthy subjects and $148.66 \pm 23.58 \mathrm{mg} / \mathrm{dL}$ in diabetic patients $(p<0.001$, Table II). The mean FBS was 139.84 $\pm 30.68 \mathrm{mg} / \mathrm{dL}$ in low zinc level group in contrast to 
Table II: Comparison of means of variables with normal and low zinc levels, diabetic and control and good and poor glycemic control.

\begin{tabular}{|c|c|c|c|c|c|c|c|c|c|}
\hline Variables & Low zinc level & Normal zinc level & $p$-value & Diabetic & Control & $p$-value & $\mathrm{HbA} 1 \mathrm{c}<7 \%$ & $\mathrm{HbA} 1 \mathrm{c}>7 \%$ & $\mathrm{p}$-value \\
\hline Age & $51.9 \pm 10.5$ & $52.8 \pm 10.2$ & 0.408 & $52.3 \pm 10.3$ & $52.5 \pm 10.4$ & 0.806 & $52.5 \pm 10.9$ & $52.2 \pm 10.2$ & 0.857 \\
\hline BMI & $32.7 \pm 6.3$ & $31.9 \pm 5.6$ & 0.242 & $32.6 \pm 5.8$ & $32.0 \pm 6.1$ & 0.292 & $32.5 \pm 6.8$ & $32.6 \pm 5.5$ & 0.869 \\
\hline Systolic BP & $174.9 \pm 26.5$ & $133.9 \pm 28.3$ & $<0.001$ & $185.1 \pm 11.6$ & $119.5 \pm 7.5$ & $<0.001$ & $186.1 \pm 11.8$ & $184.7 \pm 11.6$ & 0.474 \\
\hline Diastolic BP & $100.9 \pm 13.1$ & $83.5 \pm 13.1$ & $<0.001$ & $105.7 \pm 6.7$ & $76.8 \pm 5.3$ & $<0.001$ & $105.1 \pm 6.4$ & $106.1 \pm 6.4$ & 0.025 \\
\hline FBS & $139.8 \pm 30.6$ & $104.8 \pm 26.1$ & $<0.001$ & $148.6 \pm 23.5$ & $92.4 \pm 7.8$ & $<0.001$ & $146.1 \pm 24.1$ & $149.4 \pm 23.4$ & 0.397 \\
\hline $\mathrm{HbA} 1 \mathrm{c}$ & $8.9 \pm 2.1$ & $5.7 \pm 2.3$ & $<0.001$ & $9.7 \pm 1.1$ & $4.5 \pm 0.3$ & $<0.001$ & $6.7 \pm 0.2$ & $10.1 \pm 4.8$ & $<0.001$ \\
\hline Cholesterol & $249.3 \pm 4.1$ & $186.8 \pm 47.3$ & $<0.001$ & $267.1 \pm 18.7$ & $162.4 \pm 17.6$ & $<0.001$ & $270.9 \pm 18.8$ & $265.8 \pm 18.6$ & 0.102 \\
\hline Triglyceride & $244.9 \pm 57.5$ & $163.1 \pm 58.4$ & $<0.001$ & $265.3 \pm 30.7$ & $134.1 \pm 21.8$ & $<0.001$ & $265.6 \pm 40.2$ & $265.3 \pm 27.3$ & 0.953 \\
\hline LDL & $160.9 \pm 26.1$ & $136.9 \pm 23.1$ & $<0.001$ & $167.8 \pm 20.7$ & $127.2 \pm 14.8$ & $<0.001$ & $170.8 \pm 18.6$ & $166.8 \pm 21.2$ & 0.245 \\
\hline Zinc & $62.3 \pm 5.4$ & $84.9 \pm 10.7$ & $<0.001$ & $66.5 \pm 11.3$ & $82.6 \pm 12.2$ & $<0.001$ & $73.83 \pm 9.5$ & $67.6 \pm 10.3$ & $<0.001$ \\
\hline
\end{tabular}

Table III: Pearson correlation of zinc level with other variables.

\begin{tabular}{|c|c|c|c|c|c|c|c|c|c|c|}
\hline Groups & Pearson & Age & BMI & SPB & DBP & FBS & $\mathrm{HbA1C}$ & Cholesterol & Triglycerides & LDL \\
\hline Zinc in control group & Correlation & -0.043 & -0.083 & -0.111 & 0.153 & -0.93 & 0.159 & 0.108 & 0.066 & 0.1040 \\
\hline$(\mathrm{N}=192)$ & $\mathrm{p}$-value & 0.557 & 0.254 & 0.126 & 0.034 & 0.198 & 0.027 & 0.138 & 0.365 & 0.150 \\
\hline Zinc in diabetic group & Correlation & 0.72 & -0.033 & -0.035 & -0.006 & -0.004 & -0.24 & 0.073 & -0.087 & 0.001 \\
\hline$(\mathrm{N}=200)$ & $p$-value & 0.309 & 0.640 & 0.621 & 0.931 & $<0.001$ & $<0.001$ & 0.308 & $<0.001$ & 0.984 \\
\hline Zinc in all subjects & Correlation & 0.003 & -0.078 & -0.561 & -.511 & -0.478 & -0.527 & -0.514 & -0.543 & -0.396 \\
\hline$(\mathrm{N}=392)$ & $\mathrm{p}$-value & 0.949 & 0.124 & $<0.001$ & $<0.001$ & $<0.001$ & $<0.001$ & $<0.001$ & $<0.001$ & $<0.001$ \\
\hline
\end{tabular}

$104.88 \pm 26.12 \mathrm{mg} / \mathrm{dL}$ in normal zinc level group $(p<0.001$, Table II). The mean $\mathrm{HbA} 1 \mathrm{c}$ was 4.502 $\pm 0.383 \%$ in healthy subjects and $9.77 \pm 1.059 \%$ in diabetic patients $(p<0.001$, Table II). The mean $\mathrm{HbA} 1 \mathrm{c}$ was $8.91 \pm 2.16 \%$ in low-zinc level group in contrast to $5.69 \pm 2.3$ in normal zinc level group $(p<0.001$, Table II). High FBS and $\mathrm{HbA} 1 \mathrm{c}$ were associated with diabetic and low zinc level groups $(p<0.001)$. Serum cholesterol, LDL and triglyceride levels were significantly high in diabetic group and low-zinc level group compared to control group and normal zinc level group, respectively $(p<0.001)$.

Good glycemic control $(\mathrm{HbA} 1 \mathrm{c}<7 \%)$ was $23.5 \%$ in diabetic group. The results of sub-analysis of diabetic group in good glycemic control group ( $\mathrm{HbA} 1 \mathrm{c}<7 \%$ ) and poor glycemic control group $(\mathrm{HbA} 1 \mathrm{c}>7 \%)$ revealed that there was a significant difference between the two groups regarding zinc level, but no significant difference in age, BMI, blood pressure, and lipid levels (Table II).

The serum zinc level was negatively associated with FBS, HbA1c, and triglycerides $(p<0.001)$; but not associated with BMI $(p=0.640)$, age $(p=0.309)$ or blood pressure on Pearson correlation in diabetic group (Table III). There was no significant relationship between zinc level and other variables on Pearson correlation in control group (Table III).

\section{DISCUSSION}

This study revealed that diabetic subjects had significantly low mean zinc levels than control subjects $(p<0.001)$. These results were consistent with the study done by Sahria and Goswami, 12 which also showed low level of zinc in diabetic patients compared to their control $(p<0.001)$. This finding also concurred with studies done by Saha-roy et al. ${ }^{13}$ and Naila et al., ${ }^{14}$ in which, serum zinc was found to be significantly lower in diabetic group. Al-Maroof et al. also observed significantly lower serum zinc levels in diabetics than in control subjects. 15 Marchesini et al. explained low zinc in the diabetic population was due to the decreased gastrointestinal absorption and increased urinary excretion. 16 In one study, the zinc levels were reported similar in diabetic and control subjects. ${ }^{17}$ On the contrast, study done by Mumza et al. revealed high zinc levels in diabetic patients. ${ }^{9}$ The same finding was reported by Osman et al. that high concentration of zinc was associated with type 2 DM. ${ }^{18}$ The effect of zinc on insulin secretion is biphasic, that is, very high or very low zinc plasma concentrations impair insulin secretion. ${ }^{19}$

There was no significant difference in zinc level regarding age of the subjects $(p=0.408)$, as it was similar to the study done by Naila et al. ${ }^{14}$ In this study, there was no significant difference in male and female patients regarding zinc level $(p=0.082)$, which was similar to previous studies done by Sahria and Goswami. ${ }^{12}$ In this study, there was no significant difference in zinc concentration regarding BMI of the subjects $(p=0.242)$, although it was reported in a previous study that plasma zinc levels were lower in obese individuals. 20 It was observed that the mean fasting blood glucose in type $2 \mathrm{DM}$ cases was found to be very significantly higher than that of the controls $(p<0.001)$. The FBS was negatively correlated with serum concentration of zinc $(r=0.478$, $p<0.001)$ which was not similar to the study done by Mumza et al. $(p=0.334)$ and Naila et al. $(p=0.81), 9,14$ where there was no relation of zinc concentration with FBS.

In the present study, it was observed that the mean $\mathrm{HbA} 1 \mathrm{C}$ concentration in type $2 \mathrm{DM}$ cases had an inverse 
relation with serum zinc concentration. The zinc level was significantly low in patients with poor glycemic control compared to patients with good glycemic control; that means having lower values of $\mathrm{HbA} 1 \mathrm{C}$ have higher values of serum zinc concentration and vice versa. The Pearson correlation coefficient ' $r$ ' is found to be -0.527 which also established the strong negative correlation between these two parameters $(p<0.001)$.

Sahria and Goswami also reported negative relationship between $\mathrm{HbA} 1 \mathrm{c}$ and zinc concentration with ' $r$ ' value of 0.804.12 Tripathy et al. found a significant negative correlation between serum zinc and $\mathrm{HbA} 1 \mathrm{C}$ percentage with ' $r$ ' value of -0.408 ; and diabetic subjects of the study were found to have lower levels of zinc in serum as compared with healthy controls. ${ }^{8}$ The findings of the present study were also consistent with Al-Maroof et al., 15 who showed significant negative correlation between serum zinc concentration and $\mathrm{HbA} 1 \mathrm{c} \%$ value in the diabetic group and found correlation coefficient ' $r$ ' to be -0.33 . In view of the above, it may be concluded that there is significant reduction of serum zinc in type $2 \mathrm{DM}$ patients; although it is still not clear which came first, the effects of DM and hyperglycemia on zinc metabolism or the effects of alterations in zinc homeostasis on carbohydrate metabolism. There are evidences that hyperglycemia interferes with the active transport of zinc back into the renal tubular cells leading to more urinary excretion of zinc. Moreover, zinc also increases insulin sensitivity by increasing the binding ability of insulin to its receptors. ${ }^{8}$

In this study, the low serum zinc level was associated with high cholesterol, triglycerides, and LDL levels $(p<0.001)$. The study done by Seo et al. revealed that serum zinc levels in men were negatively associated with elevated FBS and positively associated with elevated triglycerides. ${ }^{21}$ On the other hand, there was no significant relationship found in women regarding serum zinc level and triglycerides. On the other hand, Seo et al. found a negative association between serum zinc and HDL cholesterol levels in both men and women. ${ }^{21}$ In this study, the data of HDL was not available, therefore no statistical correlation done. The effect of zinc on lipid profile and blood pressure was documented also in some other studies. One study revealed that zinc supplementation decreases triglycerides, cholesterol, LDL, and BP after 12 weeks of therapy. ${ }^{22}$ The issue whether serum zinc levels are associated with change in plasma lipids is controversial. Ghasemi et al. found a positive correlation between serum zinc levels and triglycerides in Iranian men, 23 whereas no association was observed between serum zinc concentrations and lipid profiles in Lebanese population. ${ }^{24}$

In this study, the systolic and diastolic blood pressures were negatively correlated with serum zinc level (SBP ' $r$ ' value -0.561 , DBP ' $r$ ' value $-0.511, p<0.001$ ). This was consistent with other study done on type 2 diabetic patients to see the effect of vitamin/minerals (including zinc) on blood pressure, which revealed there was significant improvement in blood pressure after vitamin/mineral supplements. ${ }^{25}$

There are some limitations of this study results. First, it was cross-sectional study so cause and effect relationship between diabetes and low zinc level cannot be established. Second, in this study other minerals not done concurrently with zinc level (like magnesium, chromium or copper) to know the influence of these trace elements on serum zinc level. Therefore, low zinc level could be due to some effects of alteration of other minerals, especially copper. Third, the level of HDL was not available to make the statistical relationship with zinc level. Although these were the limitations but this is one of the few studies done in the Middle East population and could be first study from Kingdom of Saudi Arabia. This study not only showed the relationship of FBS and $\mathrm{HbA1C}$, but also revealed relationship of LDL and TG levels.

\section{CONCLUSION}

Patients with type 2 DM had significantly low level of zinc that could be the cause of development of diabetes or may be a contributing factor. There was a negative relationship among serum zinc and FBS; and HBA1C LDL cholesterol, triglycerides and blood pressure. Further investigations are warranted to confirm the association between serum zinc levels, type $2 \mathrm{DM}$ and lipid profiles.

\section{REFERENCES}

1. World Health Organization (WHO): Fact Sheet 2014; http://www.who.int/mediacentre/factsheets/

2. Alqurashi KA, Alijabri KS, Bokhari SA. Prevalence of diabetes mellitus in a Saudi community. Ann Saudi Med 2011; 31:19-23.

3. Pan HZ, Zhang L, Guo MY, Sui H, Li H, Wu WH, et al. The oxidative stress status in diabetes mellitus and diabetic nephropathy. Acta Diabetol 2010; 1:71-6.

4. Chausmer AB. Zinc, insulin and diabetes. J Am Coll Nutr 1998; 17:109-15.

5. Song MK, Rosenthal MJ, Naliboff BD, Phanumas L, Kang KW. Effects of bovine prostate power on zinc, glucose and insulin metabolism in old patients with non-insulin dependent diabetes mellitus. Metabolism 1998; 47:39-43.

6. Jindal RM, Taylor RP, Gray DW, Esmeraldo R, Morri PJ. A new method for quantification of islets by measurement of zinc content. Diabetes 1992; 41:1056-62.

7. Anderson RA, Roussel AM, Zouari N, Mahjoub S, Matheau JM, Kerkeni A. Potential antioxidant effects of zinc and chromium supplementation in people with type 2 diabetes mellitus. J Am Coll Nutr 2001; 20:212-8.

8. Tripathy S, Sumathi S, Bhupal Raj G. Minerals nutritional status of type 2 diabetic subjects. Int J Diabetes Dev Ctries 2004; 24:27-8. 
9. Mamza YP, Abdullahi Z.B, Gali RM, Mshelia D, Genesis RY, Habu SA. Status of serum zinc and magnesium among type 2 diabetic subjects in maiduguri. J Dent Med Sci 2016; 15 : 66-70.

10. Survey Monkey (https://www.surveymonkey.com/mp/samplesize-calculator/)

11. Johnsen $\mathrm{O}$, Eliasson R. Evaluation of a commercially available kit for the colorimetric determination of zinc. Int J Androl 1987; 10:435-40.

12. Saharia GK, Goswami RK. Evaluation of serum zinc status and glycated hemoglobin of type 2 diabetes mellitus patients in a tertiary care hospital of Assam. J Lab Physicians 2013; 5:30-3.

13. Saha-Roy, Pal S, Bera S, Choudhury K, Bhattacharya A, Sen $G$, et al. Status of serum magnesium, zinc \& copper in patients suffering from type-2 diabetes mellitus. $J$ Drug Deliv Ther 2014; 4:70-2.

14. Masood N, Baloch GH, Ghori RA, Memon IA, Memon MA, Memon MS. Serum zinc and magnesium in type-2 diabetic patients. J Coll Physicians Surg Pak 2009; 19:483-6.

15. Al-Maroof RA, Al-Sharbatti SS. Serum zinc levels in diabetic patients and effect of zinc supplementation on glycemic control of type 2 diabetics. Saudi Med J 2006; 27:344-50.

16. Marchesini G, Bugianesi E, Ronchi M, Flamia R, Thomaseth K, Pacini G. Zinc supplementation improves glucose disposal in patients with cirrhosis. Metabolism 1998; 47:792-8.

17. Zargar AH, Shah NA, Masoodi SR, Laway BA, Dar FA, Khan AR, et al. Copper, zinc, and magnesium levels in non-insulin dependent diabetes mellitus. Postgrad Med J 1998; 74:665-8
18. Osman E, Levent K, Nuriye U, Nazife K, Baysal K, Ruhan K, et al. Correlations of serum $\mathrm{Cu}+2, \mathrm{Zn}+2, \mathrm{Mg}+2$ and $\mathrm{HbA} 1 \mathrm{c}$ in type 2 and type 2 diabetes mellitus. Turk $J$ Endocrinol Metab 2004; 8:75-9.

19. Figlewicz DP, Heldt A, Forhan SE, Grodsky GM. Effect of exogenous zinc on insulin secretion in vitro. Endocrinology 1980; 108:730-2.

20. Marreiro DN, Fisberg M, Cozzolino SM. Zinc nutritional status and its relationships with hyperinsulinemia in obese children andadolescents. Biol Trace Elem Res 2004; 100:137-49.

21. Seo JA, Song SW, Han K, Lee KJ, Kim HN. The associations between serum zinc levels and metabolic syndrome in the Korean population: Findings from the 2010 Korean national health and nutrition examination survey. PLoS One 2014; 9:e105990.

22. Ardekani MF, Karimi M, Mohammadi SM, Forough N. Effect of zinc sulfate supplementation on lipid and glucose in Type 2 diabetic patients. Pak J Nutr 2008; 7:550-3.

23. Ghasemi A, ZahediasI S, Hosseini-Esfahani F, Azizi F. Gender differences in the relationship between serum zinc concentration and metabolic syndrome. Ann Hum Biol 2014; 41:436-42.

24. Obeid $O$, Elfakhani $M$, Hlais $S$, Iskandar $M$, Batal $M$, Mouneimne $\mathrm{Y}$, et al. Plasma copper, zinc, and selenium levels and correlates with metabolic syndrome components of lebanese adults. Biol Trace Elem Res 2008; 123:58-65.

25. Farvid MS, Jalali M, Siassi F, Saadat N, Hosseini M. The impact of vitamins and/or mineral supplementation on blood pressure in type 2 diabetes. J Am Coll Nutr 2004; 23:272-9. 